\title{
Avaliação Pós-Ocupação (APO) segundo os critérios técnico-estético e técnico-funcional Estudo de caso: Faculdade de Ciências Aplicadas da Unicamp (FCA-Limeira).
}

\section{Raquel Ursini Tavares de Carvalho*, Gerusa de Cássia Salado.}

\section{Resumo}

Segundo Ornstein (1992), a Avaliação Pós-Ocupação (APO) visa melhorar a qualidade de vida dos usuários das edificações e produzir conhecimento sistematizado sobre o ambiente e as relações ambiente-comportamento. $O$ presente trabalho possui como objeto de estudo a Faculdade de Ciências Aplicadas da UNICAMP (FCA), localizada em Limeira-SP, contando com aproximadamente 3000 usuários que frequentam diariamente as edificações, faz com que a aplicação da APO seja oportuna, pois possibilita avaliar o desempenho do espaço resultante ante aquele proposto originalmente e a satisfação dos usuários.

Palavras-chave:

Avaliação Pós-Ocupação; Relação Ambiente-Usuário; Desempenho de edificações.

\section{Introdução}

Em média, alunos passam um terço de seus dias no interior de edifícios escolares, no qual a ambientação e decisões do projeto do edifício acabam influenciando diretamente sobre o conforto, saúde e na aprendizagem dos alunos que o frequentam (SANOFF, 2003). Segundo Ornstein (1992), a Avaliação Pós-Ocupação (APO) visa melhorar a qualidade de vida dos usuários das edificações e produzir conhecimento sistematizado sobre o ambiente e as relações ambiente-comportamento.

o ambiente e as relações ambiente-comportamento. Este tema vem sendo discutido há mais de 40 anos, buscando medir a influência que 0 ambiente possui sob 0 comportamento humano. Ornstein (1992, p. 23) define APO como: "A APO pretende, a partir da avaliação de fatores técnicos funcionais, econômicos, estéticos e comportamentais do ambiente em uso, e tendo em vista tanto a opinião de técnicos, projetistas e cliente, como também dos usuários, diagnosticar aspectos positivos e negativos, definindo para este último caso, recomendações."

Estes diagnósticos de fatores positivos e negativos do ambiente devem compor um banco de dados que será utilizado em próximos projetos para aprimorar e embasar possíveis mudanças pensando no conforto do usuário, assim como propor soluções e melhorias adequadas para os pontos negativos citados.

A APO é uma opção eficiente para realimentação de projetos com conceitos padronizados e de controle de qualidade do ambiente construído no decorrer da sua vida útil (ORNSTEIN, 1992).

Ornstein (1992), classifica a APO em seis aspectos ou categorias e no objeto de estudo desta pesquisa, salas de aula e de trabalho administrativo da FCA-Unicamp, serão enfatizados os aspectos Técnico Funcional e Técnico Estético.

\section{Resultados e Discussão}

O objeto de estudo deste trabalho é a Faculdade de Ciências Aplicadas da UNICAMP (FCA), localizada no bairro Jardim Santa Luiza, Limeira - SP, inaugurada no ano de 2009.

O terreno possui uma área de $485 \mathrm{mil}$ m2 e aproximadamente $30 \mathrm{mil} \mathrm{m} 2$ de construídos, Neste contexto, e considerando o tempo hábil para o desenvolvimento dessa pesquisa, definiu-se como ambientes desta avaliação: 04 salas de aula da graduação.

Para o cálculo da amostra que será utilizada, foi utilizada a população total de professores + alunos da graduação + alunos da pós-graduação + funcionários, finalizando com um total de 3136 pessoas. O cálculo foi feito pela fórmula de determinação de amostra para populações finitas com um grau de confiança de $95 \%$ e $5 \%$ de margem de erro, obtendo assim uma amostra de 343 pessoas.

Será aplicado nos próximos meses questionários prélaborados na amostragem para levantamento e análise de dados da pesquisa.

\section{Conclusões}

A FCA conta com cerca de 3000 usuários que frequentam diariamente as edificações, segundo anuário estatístico do ano de 2017, o que faz a aplicação da APO oportuna, pois possibilita avaliar o desempenho do espaço resultante ante aquele proposto originalmente e a satisfação dos usuários. Após a aplicação dos questionários e análise dos dados obtidos nos próximos meses, teremos conclusões a respeito da relação ambiente-usuário dentro do espaço da Universidade.

\section{Agradecimentos}

PIBIC - UNICAMP | SAE - UNICAMP

ORNSTEIN, Sheilla. AVALIAÇÃO PÓS-OCUPAÇÃO (APO) DO AMBIENTE CONSTRUÍDO. Editora da Universidade de São Paulo (edusp) -, São Paulo, 1992

ANUÁRIO ESTATÍSTICO AEPLAN UNICAMP. Disponível em: https://www.aeplan.unicamp.br/anuario/anuario.php. Acessado em $06 / 12 / 2018$

ORNSTEIN, Sheila Walbe; ROSARIO, Ono; SIMONE, Villa; ANA, França (colab.) Avaliação Pós-Ocupação - da teoria à prática. São Paulo, Editora Oficina de Textos, 2018 